$\star$ Rhizomes: Cultural Studies in Emerging Knowledge: Issue 34 (2018)

\title{
Eric Gordon and Paul Mihailidis, eds., Civic Media
}

\author{
Review by Doreen Piano
}

Eric Gordon and Paul Mihailidis, eds. Civic Media: Technology/Design/Practice, Cambridge, MA: The MIT Press, 2016.

During my ongoing attempts to eliminate animal products from my diet, I have expanded my Instagram and Twitter accounts to include pro-vegan, farm animal sanctuaries and animal liberation organizations' feeds. The content ranges from photos of vegan meals, recipes, and memes to images and videos of anti-factory farming protests, animal rescues, and animals being slaughtered or abused. Given that most people aren't part of the factory farming industry (or haven't been to a recent Morrissey concert when he performs "Meat is Murder"), it's easy enough to stay in denial about the torment and suffering those neatly packaged displays of meat and dairy at the grocery store embody (even if it is organic or 'humanely raised'). I me, and perhaps others, these daily reminders I see on my feed act as a form of resistance to normalizing factory farm meat and its attendant abus In addition, these sites allow me to contribute to raising awareness, even in a minor way, through sharing, liking, and financially supporting those defending and rescuing farm animals. Making visible issues such as this one and being able to participate easily, whether it is animal suffering, polic violence or current immigration issues by sharing/connecting on social media and other digital platforms, are some of the civic strategies and practices illustrated in this volume of essays.

A main claim by the editors, Eric Gordon and Paul Mihailidis, is that the range of practices represented in the collection as civic participation would I be considered as such within older definitions of the term. In fact, by treating the term civic as malleable and open to interrogation, the editors pres $\epsilon$ readers with a view of what civic engagement looks like in the $21^{\text {st }}$ century and how practices from coding, hacking and visualizing data to hashtag and market-based activism using social media achieve these goals. By expanding the term "civic engagement" to include how technology contribut to our capacity to participate in multiple publics, such as those I illustrated above, they argue not only for a broader understanding of civic participation but also that civic media itself, due to the multiple ways in which its tools, practices, and technologies are being used, must not be ossified but "differentiated" (5). For this reason, the case studies at the end of each of the six sections make up a decent percentage of the book's 6 pages, acting to illuminate the location-specific details of how new civic theories are achieving (or not) their goals. While some essays feature engagement with online publics that challenge critics' contempt for 'slacktivism' such as a study based in Australia of changing Facebook profiles tı the Human Rights Campaign logo in 2013 to create visual solidarity (and in some cases opposition and parody) among supporters of gay marriage (see Robards and Buttigieg), a substantial part of the book is devoted to exposing media practices occurring across numerous public spheres beyol social media that include universities, governments and NGOs, community centers and more anarchistic, underground DIY uses of media by hacker and social movement groups. In other words, this is a collection suitable for graduate seminars in digital media as well as interdisciplinary scholars addressing issues in communities beyond the university.

The volume's diversity is represented not only by the varied social spaces where civic participation occurs, but also in its trans-disciplinary approacl seen in its organization of sections that begins with "The Big Picture" and moves through "Systems + Design," "Play + Resistance," "Learning +Engagement," "Community + Action," and ending with a section on "Research + Funding." Alongside requisite disciplines such as media, digital, a communication studies, other disciplines represented are political science, urban studies, fine art and architecture, humanities, critical pedagogy, computer science, creative writing, and youth studies. What holds this "example-rich collection" together, the editors maintain, is an underlying assumption that the volume produces new knowledge while also being able to "question how that knowledge is contributed" (20).

In this respect, this volume is not a glorious embracing of digital technology's affordances at the expense of eliding its perils. Rather, it has a decider second generation digital media scholarship feel in which digital technologies are both embraced and interrogated for their civic potential. In fact, th volume leads with a dystopic essay, "Democracy in the Digital Age" by Peter Levine, that argues that maintaining a democratic state is constantly challenged by the influx of digital technologies in our personal and public lives. He focuses on what he sees as the main challenges: precision and pervasiveness: being able to amass a lot of data from citizens can influence certain normative or regressive behaviors by a wealthy elite. Citing ICE's digital surveillance techniques of illegal immigrants under the Obama administration that increased the number of deportations in addition to how th former president amassed a mountain of consumer data for his 2012 run, provide Levine examples of how digital media's relationship to democracy "intentionally dark." A final conclusion he makes is that despite offering empowerment to some historically silenced groups, new media environment are more frequently used by a wealthy minority to incur influence.

On the other hand, the majority of essays in each of the sections reveal the plasticity of digital tools to be adapted and repurposed in ways many of cannot imagine. For example, a case study in the "Play \& Resistance" section focuses on the use of "mobile money" as a method to sustain Somali informal economies where a more formal banking system doesn't exist. With a smartphone, Somalians on the ground can connect with a diaspora-r economy that provides financial support for those unable to access traditional banking systems (See Stremlau). These lesser known uses of technology are juxtaposed with more broadly known media projects such as the It Gets Better Project and the \#epicfail of the MyNYPD hashtag. 
Several essays, especially those in the first section titled "The Big Picture," provide new models for rethinking the role of social media activism, takir issue with the often derogatory term "slacktivism," shorthand for pressing a button, sharing a link, signing an online petition or contributing to a GoFundMe, are as opposed to on the ground organizing meetings, applying legal pressure on corporations, going to protests, or especially putting oneself on the line by being arrested, even beaten, for a particular cause. Ethan Zuckerman's essay takes issue with the concept of "slacktivism" by creating a theory of social action that involves "thick" and "thin" participation, allowing for a broader range of activities to be viewed as activism. As several authors point out, it is hard to quantify the effects of a hashtag on actual social change, yet using digital media in this way allows for more people to be involved through sharing with multiple known and unknown publics; thus outreach becomes a goal that may, in some cases, influence change. Connecting to these differing digital networks acts both to increase the scope of the network and at the same time becomes what Bennett and Segerberg define as "an act of personal expression....achieved by sharing ideas and actions in trusted relationships" (95).

The section "System + Design" covers issues related to "open government" initiatives such as the one that President Obama signed into office in $2 C$ "to encourage public institutions to innovate to improve people's lives" (Novecek 150) and data visualization projects that allow for more participatio and trust in government, local and national, by generating conversations from the ground up rather than top down (See Williams). Several essays in "Play + Resistance" challenge assumptions about technology's innate efficiency, calling for ways to highlight "messiness, disruption, and the playin! with rules and boundaries" (See Gordon and Water). Thus, digital media affordances are more about experimentation and manipulation rather than efficiency and precision. Another form of play, what Beth Coleman describes as an "urban hack," works against Big Data's capacity for quantifying spatial information and focuses more on re-imaging urban space in terms of a digital drift or derive, focused on affective interactions with one's physical environment.

This is a hefty, slightly intimidating (due to its scope) yet enticing book, both in content (6 sections, 42 chapters, 612 pages) and physical weight; its futuristic geometric cover hints at the forward-thinking that lurks within. The editors have excelled not only at providing multiple case studies that cross interdisciplinary boundaries but organizing the book so that the blend of scholarly approaches and methodologies makes for a cohesive read chronological sequence while also lending itself to a "choose your own adventure" approach. Published in 2016, one has to wonder how the book's contents would have changed based on the 2016 US national election. Yet post-election, Civic Media: Technology, Design, Practice provides reader with a whiff of hope during what many progressives and liberals view as dreary times. Climate change, the rise of nationalism in Western countries a its attendant xenophobia, endless war, state-sanctioned violence and surveillance, and the refugee crisis, to name a few issues, seem even more dil in Trump's America. Fortunately for those of us who read even a few of the selected essays and/or take a look at the companion website The Civic Media Project (where, the editors tell us, there are a hundred more case studies of media in action), we don't have to succumb to the doom-andgloom rhetoric promoted by many mainstream media outlets, most dramatically proclaimed by the Jeff Bezos-owned Washington Post with its post election slogan: Democracy Dies in Darkness. While I imagine the book was crafted for graduate level study and interdisciplinary scholars, it also seems pertinent to anyone interested in how digital media has become embedded at every level of our daily lives, how it is used with intention by grassroots groups, individuals, and those working in civic and political institutions, and how there is an ever-present challenge related to its misuse.

\section{Cite this Review}

https://doi.org/10.20415/rhiz/034.r03

RHIZOMES ISSN 1555-9998 $\star 230$ East Hall Bowling Green State University Bowling Green, OH 43403

Editors: Ellen Berry and Carol Siegel. Reviews editor: Craig J. Saper. Technical editor: Helen J Burgess 